\title{
Editorial
}

\section{Why We Laugh and What Makes Us Laugh: The Enigma of Humor}

\author{
Arthur Asa Berger ${ }^{* a}$ \\ [a] Broadcast and Electronic Communication Arts at San Francisco State University, San Francisco, USA.
}

\begin{abstract}
Humor (and related concerns such as the nature of comedy and of laughter) is an enigmatic subject that has perplexed our greatest thinkers from Aristotle's time to the present. There are four competing theories that explain humor, each of which argues that all humor is based on: superiority, incongruity, cognitive problems in processing humor and psychoanalytic perspectives (such as masked aggression).
\end{abstract}

Europe's Journal of Psychology, 2013, Vol. 9(2), 210-213, doi:10.5964/ejop.v9i2.599

Received: 2013-03-06. Accepted: 2013-03-06. Published: 2013-05-31.

${ }^{*}$ Corresponding author at: 118 Peralta Avenue, Mill Valley, CA 94941 USA. E-mail: arthurasaberger@gmail.com

This is an open access article distributed under the terms of the Creative Commons Attribution License

(http://creativecommons.org/licenses/by/3.0), which permits unrestricted use, distribution, and reproduction in any medium, provided the original work is properly cited.

Aristotle explained that comedy is "an imitation of men worse than average; worse, however, not as regards any sort of fault, but only as regards on particular kind, the Ridiculous." (McKeon, 1941, p. 1459). Hobbes wrote in his Leviathan "The passion of laughter is nothing else but sudden glory arising from a sudden conception of some eminency in ourselves by comparison with the infirmity of others, or with our own formerly." (as cited in Koestler, 1949 , p. 56). The use of terms such as "passion" and "sudden glory" suggest there are psychological underpinnings to the superiority theory.

The most widely accepted theory of humor is the "incongruity" theory which argues that humor is based on the difference between what we expect and what we get. Schopenhauer explained incongruity in humor writing, "The cause of laughter in every case is simply the sudden perception of the incongruity between a concept and the real objects which have been thought through it in some relation, and laughter itself is just the expression of this incongruity." Kant, another incongruity theorist, described laughter as "an affection rising from the sudden transformation of a strained expectation into nothing." The phrases "sudden perception" and "sudden transformation" suggest that there are also psychological aspects to incongruity theory.

A third theory is the "cognitive" theory which suggests that our minds haven't evolved enough for us to understand humor but that it involves paradox, play frames and metacommunications of one kind or another. Thus, William Fry Jr., a psychiatrist, explained in his book Sweet Madness (1968, p. 153), "During the unfolding of humor, one is suddenly confronted by an explicit-implicit reversal when the punch line is delivered. The reversal helps distinguish humor from play, dreams, etc...But the reversal also has the unique effect of forcing upon the humor participants an internal redefining of reality. Inescapably the punch line combines communication and metacommunication."

The fourth theory is the Freudian psychoanalytic theory of humor, which ties humor to masked aggression and other forces in the unconscious. As Freud wrote in his Jokes and Their Relation to the Unconscious (1963, p. 
101), "and here at last we can understand what it is that jokes achieve in the service of their purpose. They make possible the satisfaction of an instinct (whether lustful or hostile) in the fact of an obstacle that stands in its way."

Let me move now to one of the most important kinds of humorous texts-jokes. A joke can be defined as a short story, with a punch line, that generates mirthful laughter. With our understanding of the four most important theories of humor in mind, it is instructive to see how representatives of each of these theories might analyze the following joke:

A man goes to Miami for a vacation. After four days he notices he has a tan all over his body, except for his penis. So the next day he goes to a deserted area of the beach early in the morning, takes his clothes off and lies down. He sprinkles sand over himself until all that remains in the sun is his penis. Two little old ladies walk by on the boardwalk and one notices the penis. "When I was 20," she says, "I was scared to death of them. When I was 40 , I couldn't get enough of them. When I was 60 , I couldn't get one to come near me....and now they're growing wild on the beach."

Superiority theorists find this joke is amusing because we feel superior both to the man, who has elements of narcissism in his personality and his behavior-he wants to be tanned on every part of his body-and to the little old lady who revealed her problems with penises as she matured.

Incongruity humor theorists would see this joke as an example of a remarkably incongruous event-a penis sticking out of the sand on a beach. The punch line is what creates this incongruity. After the little old lady's revelations about her relations with penises at twenty, forty, and sixty, we are surprised by her statement "and now they're growing wild on the beach."

Cognitive theorists would explain that the joke assumes a play frame (as all jokes do) so we do not really believe the little old lady thinks that penises are growing wild on the beach, and why we laugh at the this joke (and all jokes and all humor) is something we cannot explain.

For psychoanalytic theorists, the joke is a reflection of the power of sexuality in human development and is based on the man's narcissism and the revelation of the little old lady's repressed longing for sexual relations. Now that she's over sixty, she can't get a penis (with a man attached to it) to come near her, but wouldn't it be wonderful for her if penises actually were growing wild on beaches...or anyplace else.

In my research on humor, I couldn't figure out which of the "why" theories of humor was best, so I decided to investigate what makes us laugh. I got the idea of looking for techniques that generate mirthful laughter from Freud, and found forty-five techniques that, I suggest, are found, in various combinations, in all forms of humor.

I explained these techniques in my book The Art of Comedy Writing and then used them to analyze the following humorous plays: Miles Gloriosus, Twelfth Night, The School for Scandal and The Bald Soprano. I was able to show, to my satisfaction at least, how Plautus, Shakespeare, Sheridan and lonesco used these techniques in their comedies. My list of these techniques follows: 

1. Absurdity
2. Accident
3. Allusion
4. Analogy
5. Before \& After
6. Bombast
7. Burlesque
8. Caricature
9. Catalogue
10. Chase Scene
11. Coincidence
12. Comparison
13. Definition
14. Disappointment
15. Eccentricity
16. Embarrassment
17. Exaggeration
18. Exposure
19. Facetiousness
20. Grotesque
21. Ignorance
22. Imitation
23. Impersonation
24. Infantilism
25. Insults
26. Irony
27. Literalness
28. Mimicry
29. Mistakes
30. Misunderstanding
31. Parody
32. Puns
33. Repartee
34. Repetition
35. Reversal
36. Ridicule
37. Rigidity
38. Sarcasm
39. Satire
40. Scale, Size
41. Slapstick
42. Speed
43. Stereotypes
44. Theme \& Variation
45. Unmasking

We can use these techniques to find out how the joke l've just analyzed generates humor. We find, at a minimum, the following:

Technique 29, mistakes. The woman who sees the penis thinks (and probably hopes) that penis can grow wild on a beach.

Technique 15, eccentricity. The man must have every inch of his body tanned. Perhaps, also, technique 37, rigidity, in more ways than one?

Technique 18, exposure. The man exposes his penis to the world and the woman exposes her sexual hunger. We do not, as a rule, expose our private parts in public spaces or our sexual desires.

If we were to reduce this joke to a formula, it would be: $29 / 15 / 18$. Reducing a joke to a formula may be seen as humorous. l'll leave it for my readers to decide which techniques explain why turning jokes into formulas might be funny.

What we learn from this exercise if that jokes are more complex than we might imagine and the best ones use a number of different techniques to achieve their goal—mirthful laughter. Laughter is also something of an enigma. Although most of us laugh many times during a typical day, I doubt that many people are able to define laughter in a satisfactory way.

This task has been done for us by a psychologist, Robert Provine. In an article in American Scientist (1996, p. 39) he writes, "A laugh is characterized by a series of short vowel-like notes...each about 75 milliseconds long that are repeated at regular intervals about 210 milliseconds apart. A specific vowel sound does not define laughter, but similar vowel sounds are typically used for the notes of a given laugh. For example, laughs have the structure 'ha-ha-ha-ha' or 'ho-ho-ho-ho' but not 'ha-ho-ha-ho." He also points out that most of our laughter comes from banal remarks we make to one another rather than jokes.

Humor, I would suggest, is an important and somewhat neglected subject and one that psychologists would do well to investigate. It is all pervasive, it is fearless, it deals with every aspect of our lives and deaths, it varies from class to class and country to country in terms of the subjects that people find funny and the techniques they use in their jokes and other forms of humor, and it has the capacity to reveal all kinds of interesting things about people who create humor and those who delight in it. 


\section{References}

Freud, S. (1963). Jokes and their relation to the unconscious. New York, NY: W.W. Norton.

Fry, W., Jr. (1963). Sweet madness: A study of humor. Palo Alto, CA: Pacific Books.

Koestler, A. (1949). Insight and outlook. New York, NY: Macmillan.

McKeon, R. (Ed.). (1941). The basic works of Aristotle. New York, NY: Random House.

Provine, R. (1996, January/February). Laughter. The American Behavioral Scientist, 84, 38-47.

\section{About the Author}

Arthur Asa Berger is Professor Emeritus of Broadcast and Electronic Communication Arts at San Francisco State University. He is the author of more than sixty books and one hundred articles on humor, media, popular culture and related concerns. He has written the following books on humor: Li'l Abner: A Study in Satire, An Anatomy of Humor, The Art of Comedy Writing, Blind Men and Elephants: Perspectives on Humor, The Genius of the Jewish Joke, and Jewish Jesters. 